\title{
Creating a Virtual Leader Development Course Using the Design Thinking Process for Innovation
}

\author{
John Hinck, Steven Davis, Justin Longmire, JB Byrnes \\ Leader Development Course, Air University, United States.
}

\begin{abstract}
This paper examines how a U.S. Air Force (USAF) faculty team reimagined and redesigned an in-person Leader Development Course (LDC) to a virtual version (vLDC). Using the Design Thinking Process for Innovation (DTPI) and action research methods, a new, virtual course was imagined, designed, tested, and improved over a six-cycle-process. Data was collected via multiple sources from 121 participants (19 faculty/staff and 102 students) and analyzed using manual coding and NVivo Software. Results are organized into 22 categories under four themes (general course design, student experience, instructor experience and faculty development, and technology experience) showing a progressive refinement with key lessons learned that led to the final creation of the new virtual course. Of the five key features in action research (actions matter, context-specific research, multiple cycles and phases, inclusion of people as research target, and reflections), participants reported that multiple cycles and reflections were most important in relation to the DTPI so that change could be enacted that reflected participant voices in the design process of the virtual course. The application of the DTPI using action research methods produced results and lessons learned in the design process that contribute to the theory and practice on developing and teaching in a virtual learning environment. The study fills a gap in the scholarly field and informs other institutions on the process, failures, and successes of course redesign to a virtual version.
\end{abstract}

Keywords: Design thinking process for innovation; action research; USAF; leader development. 


\section{Introduction}

The Leader Development Course (LDC) is an educational program that trains and teaches military/civilian leaders in the responsibilities of leading and commanding U.S. Air Force (USAF) organizations. The LDC was developed due to a leader developmental gap related to human domain skills identified in RAND (Research ANd Development) Corporation's "Improving the Effectiveness of Air Force Squadron Commanders" (RAND, 2017). One of the outcomes of the publication was the creation of the LDC, which was housed under the Eaker Center for Leadership Development within Air University (AU) located at Maxwell Air Force Base in Alabama. As the USAF's Pinnacle Institution, AU comprises several subordinate organizations that oversee enlisted education, officer education, officer accessions, and professional development for civilians and military members, along with seven academic centers and related publications and research. The Eaker Center for Leadership Development is responsible for planning and conducting the LDC.

The LDC is an 8-day intensive course of lectures, seminars, and experiential events that build skills associated with leading others in a military context (e.g., knowing self, establishing climate and culture, values-based decision making, negotiation skills, building effective teams, dealing with conflict, administering discipline and justice, physical fitness events, and coaching practice). The overall course objective is to "Improve leader development of officers and civilians approaching command selection in order to sharpen and focus leadership skills to achieve mission success through high-performing teams" (LDC-SC Smart Card, 2019). Students learn the content in week one and then, in week two, apply the knowledge in a variety of opportunities (e.g., case studies, experiential events, and virtual reality scenarios). The course culminates in a capstone experience involving augmented reality scenarios. Over 26 courses and 1500+ students, the LDC received extremely high marks by students and guests in end of course critiques and in post course surveys sent to graduates and their supervisors (Hinck \& Davis, 2021).

\section{Problem and Significance}

From 2018-2020, the LDC was delivered synchronously, or in-residence, in a classroom environment using a range of pedagogical and andragogical methods. Due to the Covid-19 outbreak, military leaders increased health protection conditions and the LDC was halted for nearly two months while USAF developed guidance and procedures to return effectively and safely to delivering content to students.

The problem that faced the LDC Faculty and AU leadership was how to transition an inresidence course to a virtual environment under pandemic realities. Leaders wanted the new virtual course to capture similar experiences to the in-person course that had an interactive 
and experiential learning environment that continued to achieve course outcomes and cognitive, affective, and behavioral learning objectives — all with high marks.

\section{Literature and Research Questions}

There is not enough scholarly work relating to developing a virtual course (Dunn, 2018; Tschimmel, 2012). There is a scholarly gap in how to design, test, and deliver a virtual course in the military environment. The Design Thinking Framework for Innovation (DTFI) does provide a way to design something new but has not been applied in reimagining how a course would operate virtually (Beckman, 2007; Liedtka, 2014). Figure 1 shows how a positive student experience is based on the interconnectedness between the human microsystem (interactions of instructors, peers, and self) and six overlapping elements - the exosystem that brings the student experience to life (Hinck \& Davis, 2021).

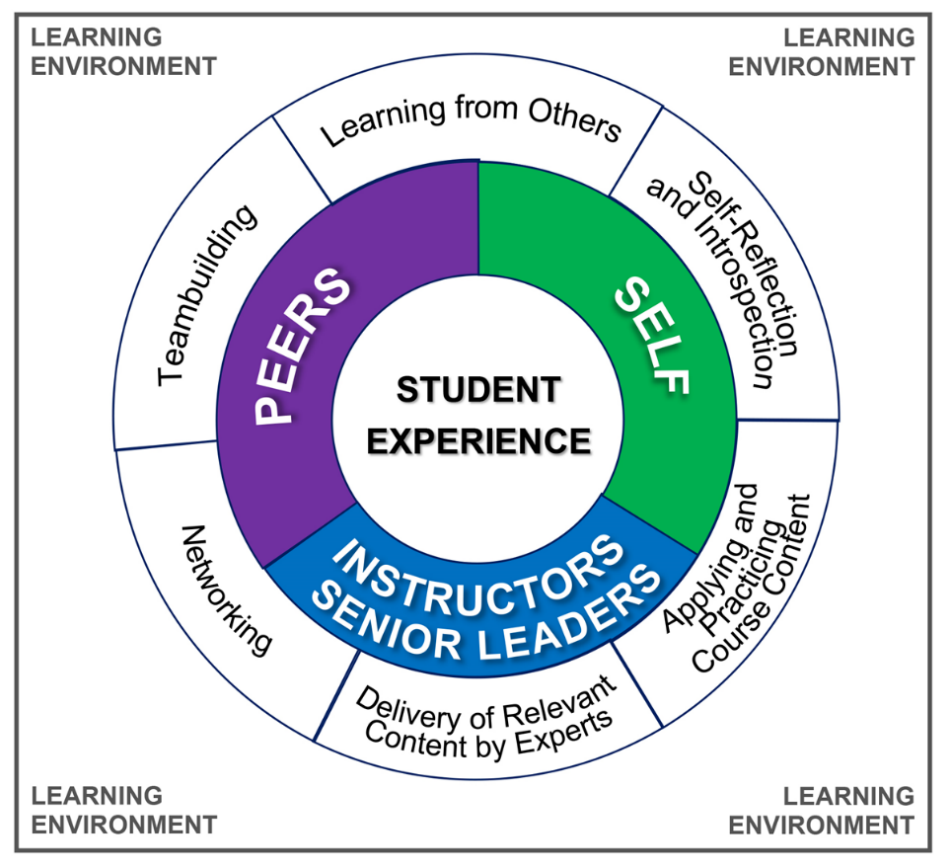

Figure 1. Student Experience Ecosystem

Action research is a philosophy and qualitative method that seeks transformative change via cycles of action, reflection, and change (Stringer, 2014; Torbert, 2004). There are five key features of action research for educators: actions matter, context-specific research, multiple cycles and phases, inclusion of people as research target, and reflections (Inoue, 2015). 
Two research questions (RQ) guided this study:

RQ1. How can faculty adjust the in-residence program to a virtual version using the Design Thinking Framework for Innovation?

RQ2. To what extent do themes or lessons emerge during the research process that influence virtual course execution?

\section{Research Design and Methods}

The research design employed six cycles of action research of action-reflection-change that overlayed the five parts of the DTPI in each cycle: emphathise, define, ideate, prototype, and test, as depicted in Figure 2. Participants included 19 faculty/staff $(\mathrm{N}=19)$ and 102 students $(\mathrm{N}=701)$. Data collection included Zoomgov chats during course execution, staff emails, and notes captured during team meetings, student end-of-course surveys, and informal interviews to follow-up on data gathered in the collection process. Data analysis involved manual coding and NVivo Software to develop codes, categories, and themes.

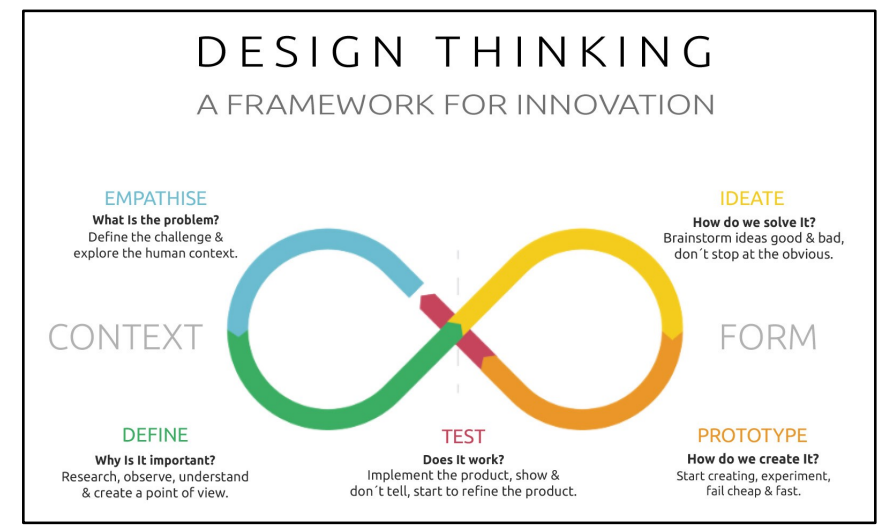

Figure 2. Design Thinking Framework for Innovation

\section{Results}

Using the DTPI, the results of the of the six cycles of action-reflection-change are shown in Table 1 and organized into duration to move from empathize-define-ideate-prototype, test phase, and over all time expressed in people hours. 
Table 1. Organization of the Six Cycles of the DTPI.

\begin{tabular}{|c|c|c|c|c|}
\hline \multicolumn{5}{|c|}{ Action - Reflection - Change } \\
\hline Cycle & Empathize & Define | Ideate | Prototype & Test & Time \\
\hline$\# 1$ & & 7.5 days & $\begin{array}{l}\text { Zoomgov discussion / } 2 \text { hours } \\
\text { Conceptual }\end{array}$ & \\
\hline$\# 2$ & & 4 days & $\begin{array}{l}\text { Alpha test / } 3 \text { hours } \\
\text { Technology platforms }\end{array}$ & $17 \mathrm{~K}+$ \\
\hline$\# 3$ & & 3 days & $\begin{array}{c}\text { Beta test } / 2.5 \text { days } \\
\text { Days } 0,1 \text {, select content }\end{array}$ & hours \\
\hline$\# 4$ & & 2 days & $\begin{array}{l}\text { Faculty development / } 6 \text { days } \\
\text { Teaching Teams \& Lesson Plans }\end{array}$ & \\
\hline$\# 5$ & & 1.5 days & $\begin{array}{l}\text { Virtual LDC \#20M / } 8 \text { days } \\
\text { Days } 0 \text { thru } 9-I O C\end{array}$ & $\begin{array}{l}1.5 \mathrm{~K}+ \\
\text { hours }\end{array}$ \\
\hline$\# 6$ & & 1 day & $\begin{array}{c}\text { Virtual LDC \#20N / } 8 \text { days } \\
\text { Days } 0 \text { thru 9-FOC }\end{array}$ & $\begin{array}{l}1.5 \mathrm{~K}+ \\
\text { hours }\end{array}$ \\
\hline
\end{tabular}

From May 2020 to June 2020, a total of 121 participants were involved (voluntarily) with over 22,000 work hours in the six stages of the design process. The time spent on the first four stages decreased with each successive cycle (\#1 thru \#4) amid multiple failures. Time spent on the last stage of testing increased with each cycle (\#5 and \#6) to get to a successful version of the new virtual course. The coding process of four cycles (pre-codes, in vivo and descriptive coding, categorical coding, and thematic coding) produced 54 primary codes and 76 secondary codes that were organized into categories and themes in refining and reimagining LDC for a virtual environment. NVivo coding supported manual coding between two researchers with $96 \%$ inter-rater reliability and two minor discrepancies that were resolved in the second coding cycle. The 22 categories are organized under the four themes that emerged during the coding process:

\#1-General Course Design

- Be clear on the desired outcomes.

- Resources will determine your bounds of reality.

- Have a process to go from concept to test.

- Expand the concept of the virtual learning environment.

- Widening the learning continuum for before-during-after student contact time.

- How course design deepens the student experience.

- Identify conditions for success amid the pandemic.

- Using technology/schedule structure to aid in connections.

- The student experience ecosystem model needed to be updated for the virtual environment and new terms/definitions are needed. 


\section{\#2-Student Experience}

- Students want opportunities for pre-work and deepening understanding of concepts.

- Breakaways are needed to break away from main room, e.g., Zoomgov breakout rooms, use of telephone to chat, social media platforms, and self-reflection/journaling.

- Must tempo the type and duration of breakaways in seminar; type, number, duration of breakouts must be done with intent and focused on student experience.

- Students want more time to connect and have an experience with each other; they prefer to avoid rapid breakouts of pairs for a few minutes to being able to have longer conversations in small groups or with the entire seminar.

\section{\#3-Instructor Experience and Faculty Development (FAC-D)}

- Need more instructors / people are needed to run vLDC as the learning environment requires more integral orchestration between actual and virtual environments.

- Optimum manning for seminar is three instructors with two instructors physically in the same seminar room and the third instructor either in the same room or from a remote location. There is a heavy reliance of collaboration in the moment to ensure learning environment is optimized and is adjusted/adapted to meet students' needs in achieving the learning objectives.

- Include the entire LDC team in FAC-D and mirror the student experience.

- Cover and delivery methods of content in morning; afternoons are instructor driven for "productive white space" of personalization of content and practice with teaching team.

- Need multiple reps using Zoomgov and "check-ride" to increase confidence of all.

\#4-Technology Experience

- Expose students to all Zoomgov functions in week 1 as well as giving them co-host and host responsibilities over course duration.

- Need standard screen names - for *instructors/LDC team, students, and guests; on Day 0 , recommending starting screen names during check-in and reinforcing on Day 1.

- Find ways to use and save student responses of chats, pictures, drawings/annotations, etc. and create a memory or moment, e.g., build a PowerPoint collage of students, words, pictures, and drawings as evidence of learning.

\section{Discussion}

Only parts of the overall discussion are presented in this paper. Based on the findings, the discussion is organized as five main lessons learned from the study. Discussions 1 and 2 are supported by existing literature. Discussions 3, 4 and 5 provide additions to the literature. 
1. Moving from a traditional in-person course to a virtual version can be done, but it must be structured. As advocated for in research fields, the Design Thinking Process for Innovation (Beckman, 2007; Dunn, 2018; Liedtka, 2014; Tschimmel, 2012;) and action research methods (Inoue, 2012; 2015; Stringer, 2014; Torbert, 2004) provided such a framework. Of the five key features in action research (Inoue, 2015), participants reported that multiple cycles and reflections were most important in relation to the DTPI so that change could be enacted that reflected participant voices in the design process of the virtual course. A virtual in residence, remote (VIR-R) Leader Development Course can be executed that aligns with the Student Experience Ecosystem (Hinck \& Davis, 2021). Students reported feeling connected, and a new student even commented: "I don't know how you did it, but you created a culture in two days... I feel more connected to you all than I do my own office, and I have a staff meeting with them every day". Another new student said, "this is the best mentoring I've received since I commissioned".

2. Teaching teams found they actually have to collaborate more to successfully hold the environment for students in seminar, which is supported in some literature (Hinck \& Davis, 2021; Liedtka, 2014; Matusov, 2001). To keep students engaged, students need to be actively participating by speaking, typing, calling another student, writing in their journal, etc. To facilitate all that interaction, instructors, are required to: remember to step in/out of the camera frame, mute their computer, coordinate breakout rooms, respond to chats, set up current and future activities, actively listen to students and watch the affective responses of students (body language, gestures, hand raises). That took 100\% effort from our experienced teaching pairs.

3. Zoomgov is the right technology because of the quality of video frames, ability to see nonverbals, and platform capabilities. We asked students to keep their videos on full-time in seminar and during lecture. Paired with our big 72" Microsoft Hubs, we were able to show 12 " 18 " video feeds of all students, which allowed instructors to observe body language and level of engagement. Knowing they were on video made students feel they were "in a classroom", especially when gestures such as raising a hand, laughing, clapping, or shaking their head proved to be effective communication tools. We used multiple Zoomgov rooms (LDC Main, Seminar 1, Seminar 2, and Student Management) and pushed students from one room to the next. Each room requires a separate paid account.

4. Specific to LDC (highly interactive, human-domain focused course): To keep the students' attention for a VIR-R LDC, the content delivery must be synchronous during the times they are on Zoomgov. Interaction among students and instructors is what keeps their attention! Pushing a video lecture "live" via Zoomgov was our only failed delivery method. Students disengaged and lost interest because it wasn't live. They attribute this to the necessity for a "holding environment". The students are NOT able to secure 100\% quiet/uninterrupted environments in their homes or offices, so they rely on the LDC environment to keep them 
engaged. When we pushed a video, LDC became "just another computer-based training they could walk away from and disengage" (student words).

5. Delivering a synchronous lecture/perspective/presentation in the auditorium is now a three-plus person job, like broadcasting a live TV show. What used to take one person on stage, now takes at least three dedicated personnel and four Zoomgov accounts. A "room manager" is required to manage, admit, mute, and respond to students' technical requests, while this or an additional person monitors student feedback. A producer focusing on muting/unmuting the presenter, switching between the cameras and "share screen" slide presentation/video clips, and managing the Hub display for the presenter. None of these duties can be done by the presenter, who has to focus on delivering content into the camera and staying on-script with the producer. Additional Zoomgov accounts are necessary to set up microphones and secondary cameras.

\section{Conclusions and Implications}

The four themes of 22 categories along with the discussion of five key lessons learned help fill a gap in the scholarly field, add new discoveries to the filed, and inform other institutions on the process, success, and failures of virtual course redesign. The application of the DTPI using action research methods produced results and lessons learned in the design process that contribute to the theory and practice on developing and teaching in a virtual learning environment. Multiple cycles and reflections that represented participant voices were keyways of informing the DTPI. The LDC has since delivered 10 versions of the new virtual course and students indicated the same high level of satisfaction and extremely impactful experience that was similarly reported in the in-person LDC.

\section{References}

Amble, N. (2012). Reflection in action with care workers in emotion work. Action Research, 10(3), 260-275.

Beckman, S.L. \& Barry, M. (2007). Innovation as a Learning Process: Embedding Design Thinking. California Management Review, vol 50, no 1, Fall 2007.

Dunn, D. (2018). Implementing design thinking in organizations: an exploratory study. Journal of Organization Design, 7:16. https://doi.org/10.1186/s41469-018-0040-7.

Hinck, J.M. and Davis, S.B. (2021). Re-Operationalizing and Measuring "Impact" of a Leader Development Course, International Journal of Teaching and Learning in Higher Education, 32(3), 427-440.

Inoue, N. (2015). Beyond actions: Psychology of action research for mindful educational improvement. New York: Peter Lang Publishing.

Inoue, N. (2012). Mirrors of the mind: An introduction of mindful ways of thinking education. New York: Peter Lang Publishing, p. 20. 
Liedtka, J. (2014). Innovative ways companies are using design thinking. Strategy \& Leadership, 42, 2, 40-45.

Matusov, E. (2001). Intersubjectivity as a way of informing teaching design for a community of learners' classroom. Teaching and Teacher Education, 17(4), 383-402.

RAND Corporation. (2018). Improving the effectiveness of Air Force Squadrons, RAND.

Stringer, E. (2014). Action research (4th ed.). Thousand Oaks, CA: SAGE.

Torbert, B. and Associates (2004). Action inquiry: the secrets of timely and transforming leadership. San Francisco, CA: Berrett-Koehler Publishers, Inc.

Tschimmel, K. (2012). Design Thinking as an effective Toolkit for Innovation. In: Proceedings of the XXIII ISPIM Conference: Action for Innovation: Innovating from Experience. Barcelona. ISBN 978-952-265-243-0.

USAF. (U.S. Air Force). (2020). LDC smart card. 